\title{
Balancing trust and control through dialogue meetings in Norwegian school district governance
}

\author{
$\emptyset$ yvind H. Henriksen ${ }^{1}$ D . Jan Merok Paulsen ${ }^{1}$
}

Received: 14 June 2019 / Accepted: 29 December 2020 / Published online: 18 January 2021

(c) The Author(s) 2021

\begin{abstract}
Increased attention has been paid to school superintendents and their role in school reforms. Still, there are few studies on dialogue meetings between actors at different levels in the school hierarchy. The current paper investigates how a superintendent balances between trust and control while supporting school development through dialogue meetings. Drawing on interviews, reflection notes, and longitudinal observational data from dialogue meetings, comprising a superintendent, subordinated school leaders, and team leaders, this action research study provides insight into requirements for productive dialogue meetings. We argue that superintendent leadership through regular dialogue meetings can foster trust-building, empowerment, and professional commitment.
\end{abstract}

Keywords Superintendent leadership · School reform · Trust versus control · Professional commitment $\cdot$ Dialogue meeting

\section{Introduction}

There is increased attention in the research literature on school superintendents and their role as intermediate system leaders related to school reform initiatives, both internationally (Cox and McLeod 2014) and in the Nordic countries (Moos et al. 2016a). In the latter context, a school superintendent is defined by three characteristics: First, he or she is responsible for primary education within the entire municipality and thus the unity of command of the school leaders in hierarchical terms. Second, the superintendent is also subordinated to a political board. Finally, at least in the Norwegian context, the superintendent is directly coupled to the top of the municipality hierarchy through permanent membership in the municipal director's senior leadership team (Paulsen et al. 2014). The superintendent is a key agent in the current study due to the unique position in the school governing hierarchy,

Øyvind H. Henriksen

oyvind.henriksen@inn.no

Jan Merok Paulsen

jampa@oslomet.no

1 Faculty of Teacher Education and International Studies, OsloMet - Oslo Metropolitan University, Pilestredet 42, N-0130 Oslo, Norway 
where the superintendent potentially can foster professional development and professional commitment through deliberate dialogue actions, learning-oriented venues, and support.

One avenue of influence is the regular dialogue meeting, a meeting between different levels in an organisation, which intends to soften the management of lower levels through cooperation instead of orders and direct instructions. In this case, it constitutes a meeting comprising a superintendent, subordinated school leaders, and team leaders. In this study, we will empirically explore theses dialogue meetings.

The mixed-role position of the school superintendent constitutes several sources of influence by mediating policy and change initiatives towards school leaders and teachers. Superintendents are mediators who try to create an appropriate match between policy goals and municipality demands, on the one hand, and professional performance in schools, on the other. Especially, mastering the delicate balance between controlling schools simultaneously with building trust in professional forums is essential in contemporary superintendent leadership. This balancing act reflects a real-life tension of leadership, as any form of organising must deal with a paradoxical tension between power and trust (Sørhaug 1996, p. 21), forming an enduring dilemma for school leaders at all levels. Leaders' capacity to exercise leadership is contingent on the trust of the people in the schools; at the same time, leaders are expected by the same people to use power in certain situations. This dilemma is echoed in two contrasting school models, external control versus professional commitment, as discussed in scholarly literature for a long time (see Rowan 1990). In line with the professional commitment model, we have found that dialogue forums between school leaders and their superintendent, to whom they are subordinated, build trust, and stimulate reflection on productive school development. Still, little attention has been paid to the content and form of dialogue meetings between actors at different levels in the school hierarchy and performing their work in dispersed locations. Notably, there are few longitudinal studies based on observational data aiming to unpack content and processes in dialogue meetings.

The current study follows this line of reasoning through an action research project with interviews, reflection notes, and longitudinal observational data from dialogue meetings, comprising a superintendent, subordinated school leaders, and team leaders. Within a theoretical framework based on trust and control, we have posted the following research question: How does a superintendent balance between trust and control in dealing with school development through dialogue meetings with school leaders? By addressing this, we can increase our insight into requirements for productive dialogue meetings and thus into school reform on a system level. If we can better understand the superintendent's role, we can take new steps towards improving school districts. We argue that superintendent leadership through regular dialogue meetings can foster trust-building, empowerment, and professional commitment.

\section{The political context of dialogue meetings}

It has been argued that mistrust-oriented forms of cooperation between the central administration and school leaders have evolved in some municipalities in Norway (Helgøy et al. 2007). The current modes of cooperation are oriented towards control, standardisation, results, and accountability. Findings from 1997 to 2007 indicate that school leaders increasingly perceived that evaluation results were more used for municipal hierarchical 
control than for initiating school development (Engeland and Langfeldt 2009, p. 10). Moos et al. (2016b) claim they.

see contemporary trends in public and educational governance in the Nordic countries that are moving towards less trust and more control in the relations between the political top-officers in the concern and the more administrative servants in the enterprise and the workplace. (p. 194)

Still, according to Berg (2015), there is a more trust-based culture at the local level than at the national level. For example, there is a high level of mutual trust between superintendents and school leaders (Paulsen and Høyer 2016). The use of dialogue meetings, a more trust-based form of cooperation, has also increased (Berg 2015, p. 345).

Dialogue meetings have roots in the concept of management dialogue-a popular governing tool within public administration in Norway-which is a dialogue meant to go from the top to the bottom of the organisation (Bukve 2009). A report based on a research and development project about how to succeed as a local education authority recommends municipalities to get more involved in school development through management dialogues about curriculum, results, and methods (Jøsendal and Langfjæran 2009). It suggests management dialogues between local politicians and the municipality's top manager, then between the top manager and leaders in the municipality's administration, and further down to school leaders, team leaders, teachers, students, and parents. The municipality in this study started with local dialogue meetings after participating in a national project focusing on dialogue.

\section{Theoretical framework}

To understand the positional conundrum of superintendents, we guide our analysis with the contrasting notions of external control and professional commitment. These overarching concepts form the backdrop of the analysis situating the superintendent towards control or trust. The essential underpinnings of trust are furthermore delved into as they help to reveal empirical aspects of trust. Lastly, we touch upon learning climate in groups since the group dynamics in dialogue meetings have a profound effect on the participants.

\subsection{External control versus professional commitment}

In an extensive policy review from 1990, new-institutional theorist Brian Rowan noted that a model he labelled an external control strategy - initiated to raise the level of educational outcomes - had gained hegemony in the USA and later evolved towards a global model after the millennium shift (Sahlberg 2011). Through bureaucratic control over curriculum and teaching (as a response to low achievements in schools), the purpose is to "produce faithful implementation of a program's preferred teaching regime, through tight restrictions on teacher autonomy and a corresponding focus on a narrow band of teaching practices" (Rowan and Miller 2007, p. 254). External control means that authorities outside schools check whether procedures are followed correctly to ensure that the mandatory agent does not suffer. State bodies, regional governors, municipal school administration, and local politicians operate within the Norwegian national quality assurance system towards school leaders within a given municipality. Specifically, external control also involves supervisory 
activities that are continuously undertaken to follow up possible mismatches in goal achievements.

A contrasting model labelled a professional commitment strategy emphasises a collaborative trust culture with teacher empowerment and professional collaboration employed at both the school level and the district level (Rosenholtz 1987; Rowan 1990). Organisational commitment among teachers has long been recognised as a critical predictor for teachers' quality of work by demonstrating that they have high status and are willing to contribute beyond what is expected of them (Bogler and Somech 2004). On the contrary, the consequences of low organisational commitment are often that "teachers converse more about poor working conditions than about teaching problems and their solutions" (Rosenholtz 1987, p. 542).

More recent works empirically investigate the symbiotic relationship in school strategy between school district administration and local schools. Xia et al. (2020) found that dimensions of professional commitment strategy appeared in areas of professional development of teachers, self-evaluation of teacher practices, and discipline policies. On the other hand, external control appeared in the areas of defining performance standards, establishing local curriculum, and defining standards for professional development. Grinshtain and Gibton (2018) found a similar co-existence of control and commitment in the context of site-based-management schools, where principals utilised their autonomy to fill the gap between these strategies. Weiner and Woulfin (2017) analysed control and commitment in the context of how a group of novice principals deployed principles labelled as "controlled autonomy" - a condition in which school leaders are expected to both make sitebased decisions and be accountable to district oversight— to increase performance. Finally, Datnow et al. (2017) bring this issue into the context of data-use, where data strategies embrace both an external control and accountability element as well as professional sensemaking at the "street-level" of the school.

\subsection{Trust}

Tschannen-Moran and Hoy (2000) defined interpersonal trust as "one party's willingness to be vulnerable to another party based on the confidence that the latter party is (a) benevolent, (b) reliable, (c) competent, (d) honest, and (e) open" (p. 556). Bryk and Schneider (2003) conceive trust as comprising respect (civility in behaviour), regard for the other's well-being, competence, and personal integrity. Louis and Murphy (2017) found an interrelation between cognitive trust-in capacities and professionalism, for example, assumptions of a competent and reliable leader-and affective trust-liking and personal affinity, for example, people are more likely to trust somebody when they feel cared for. Mayer et al. (1995) concluded that when people perceived their leaders as benevolent, acting with integrity and following their articulated intentions, the propensity of employees to engage in vulnerable and risky situations, as sharing sensitive information with their superior increased. However, subordinates look for benevolence, honesty, and openness in their leaders, and leaders look for reliability, competence, and honesty in their subordinates (Tschannen-Moran and Hoy 2000, p. 573). A benevolent superintendent wants to do good to the school leaders, which gives an air of loyalty and a sense that they are in it together. A superintendent that engages in open reflections with school leaders makes the school leaders open up as well. Meyer et al. (2017) suggest that "those in power can relieve the tensions created by differential power relationships through specific behavioural practices that signal their trust-building motives" (p. 223). In contrast, when distrust emerge "the 
goal of communication often becomes the protection of one's interest and the reduction of one's anxiety rather than the accurate transmission of ideas" (Tschannen-Moran 2014, pp. 87-88). Thus, distrust produces biased and dishonest communication, whereas trust enables openness and honesty essential for productive communication.

\subsection{Learning climate in groups}

The notion of a supportive learning climate has frequently been conceptualised as a group's psychological safety, meaning a "shared belief that the team is safe for interpersonal risk taking" (Edmondson 1999, p. 354). As such, psychological safety builds on interpersonal trust but also goes beyond this. As a group-level construct, it is characterised by a shared belief among the members that the team is a safe zone for speaking up, identifying errors, mistakes, and bringing in new perspectives. Groups where members are not penalised for making a mistake but rather are encouraged to ask for help tend to utilise the team's knowledge reservoir to improve work processes and find strategies for improvements. In Norwegian school leadership teams, at school level and district level, psychological safety in the groups has emerged as a strong predictor of professional learning (Hjertø and Paulsen 2017; Paulsen and Hjertø 2019).

\section{Methods}

A small-medium municipality in Norway, consisting of about ten primary and lower secondary schools, was chosen as a case since it was in the process of implementing dialogue meetings in the education sector. Additionally, the first author had in-depth knowledge of this process (being a former employee in the municipality), and the superintendent had signalled research interest. To better understand the purpose of dialogue meetings, and how they affected the participants' cooperation, unstructured qualitative observations of dialogue meetings, each lasting about two hours, were conducted for 18 months. With dialogue meetings each half-year, data from three dialogue meetings at each school were collected. The first author observed without participating, audio-recorded, and wrote field notes mostly concerning the themes of the dialogues and standpoints of the participants. By concentrating on a single case, we believe we have gained the depth necessary to fathom how the superintendent balances between trust and control while supporting school development through dialogue meetings.

We have taken our intervention in people's lives seriously. The superintendent expressed research interest, and he participated in developing the initial research idea. The first author presented this idea to the school leaders, and three of them volunteered to participate and wrote their consents. We have respected the privacy and anonymity of the participants (Creswell and Creswell 2018, p. 95) by not naming the municipality, by giving fictive names to schools and participants, and by changing gender on some of the participants. With asymmetrical power relations in play, we had to be especially aware of ethical power issues (Herr and Anderson 2005, p. 36), making sure we did not side with the already powerful superintendent. We were also keenly aware of the powers of a researcher, not taking an expert role, but rather being a friendly co-participant, they could trust. As the first author already knew several of the participants, open and trustful relationships established naturally. 
Since we wanted to capture the participants' intentions and understandings, the five key participants - the superintendent, his advisor, and three school leaders-reflected upon their experiences through semi-structured face-to-face interviews, including critical questioning, and reflection notes (see Appendix A for details of the data collection). The reflections were done at three junctures, constituting three cycles within a spiral of action research, with planning, acting, observing, and reflecting (Carr and Kemmis 1986). Action informed our understanding, and our understanding assisted our action. See Henriksen and Aas (2020) for more about the action research part of this study.

The five key participants gave 16 interviews, each up to one hour, and they wrote 20 reflection notes - on the content of the dialogue meetings, on the process, and on how to improve. After each half-year with dialogue meetings, they wrote a reflection note, gave an interview, and then wrote another reflection note, each about a page in length (see Appendix B for details of interviews and reflection). The interviews and the reflection notes were the primary interventions, in addition to discussing and planning dialogue meetings with the superintendent and his advisor. The goal was to grasp what was going on, but also to promote reflective practitioners, mirroring the double role of action research of doing both research and action.

In the data analysis (using NVivo), inductive and descriptive coding (Miles et al. 2014), were initially used as interesting information emerged from the data. Participation, trust, aims, openness, control, and preparation were among the first codes. Based on relevant literature, these codes were expected (Creswell and Creswell 2018, p. 195). With much data on trust and control, we pursued these two themes in more detail using deductive coding, also with the predetermined codes, benevolence, integrity, and competence. Meaningful data were identified, compared, grouped, and regrouped, and a research log with the first author's reflections served as a basis for analysis.

To secure validity, we have exposed several parts of the study (Eikeland 2006, p. 231) by bringing it into dialogues at seminars, courses, and conferences, letting colleagues critically assess its parts. We have used member checking (Creswell and Creswell 2018, p. 200), asking the participants to read and comment on an earlier draft, to check the accuracy of the descriptions and the participants' quotes and the coherence of the analysis. Triangulation (Creswell and Creswell 2018, p. 200) was used to validate the data by checking data from different individuals, and by using various methods of data collection (observations, interviews, and written notes). The challenge of being both a researcher and a practitioner in action research (Herr and Anderson 2005, p. 5), was handled by separating the two in time. The bulk of the analysis was conducted after the practitioner part ended in 2015, providing sufficient analytical distance.

\section{Findings}

The findings are presented under four headings; first, we found a mixed message of intentional control, as the superintendent intended an open dialogue, but in practice, the meetings were led and controlled by the superintendent. Second, the participants praised the meetings as venues comprising honesty and trust. Third, broad participation gave voice and empowerment to several participants by bringing more perspectives 
into the dialogue meetings. Fourth, trust and group climate are bolstered when the participants reflect on school issues with competence, openness, and benevolence.

\subsection{Mixed message of intentional control}

Two months before the dialogue meetings started, superintendent Stig sent an information letter to the schools with the following message:

We currently have considerable information on the results of diagnostic tests, national tests, exams, surveys, and so on, at the school level. [...] All this is essential management information, which should form the basis for each school's focus and prioritisation in the coming year. A dialogue meeting will be held at the school, where these results will be discussed. [...] The meeting aims to have a professional dialogue between the school and the municipality, as part of the system work the municipality is required to have.

Some weeks later, the purpose of the dialogue meetings was stated in another letter sent to the schools:

To get to know the school's strengths and challenges so that (1) the school can identify areas for improvement and make development targets; (2) the municipality can prioritise and provide local support; and (3) the municipality can direct the system with local attention.

This purpose was also written on the agenda sent to the schools before the first two sets of dialogue meetings.

At each school in the first set of the dialogue meetings, the superintendent followed up the above-mentioned letters and explicitly stated that the intention was not to control the schools, but rather to find out what was going on inside the schools and to support and back up their efforts. Stig reiterated this in the interviews: "My intention was not that the dialogue meeting should take the form of external supervision; rather, I intended a creative approach and not least to gain a richer understanding of the situation of each of the schools" (int 1). His advisor had a similar view: "We were very clear that these meetings should not serve control purposes nor supervision, but dialogue. [...] Municipalities have a responsibility to provide adequate support to each school and, therefore, must know the schools' strengths and weaknesses" (int 1). These intentions reflect the duty of municipalities, in the Norwegian governance system, to gather rich knowledge of the units under supervision to help, guide, and support the schools.

Still, the image emerging from the data is a superintendent in charge of the meetings. He set the agenda together with his advisor, led the meetings, and summed them all up, while the advisor wrote the minutes. Stig encouraged the school leaders to take charge, and a few did at the beginning, but, eventually, he ended up leading each meeting. The schools were encouraged to put issues on the agenda, and the agenda was so flexible that spontaneous discussions could arise. The participants were free to raise any topic they wanted in the meetings. School leader Aud supported this by suggesting that the participants in the meetings were on an equal footing, "It's important that we're all on the same level from a power perspective, a democratic perspective" (int 3). However, Stig also talked much and told the participants what he deemed good practice: "It disproves 
that students' backgrounds decide where they should be; it proves that your efforts as a teacher works" (dm 3 Aspen). He also told them what he deemed bad practice: "We cannot live with something that does not work" (dm 3 Aspen).

The message is mixed. This is no surprise since, according to Rowan (1990, p. 381), few schools are implementing any of the two abstract models consistently. As school leader Clara said, "It's a little like a dialogue between employer and employee, even though it's on a slightly higher level. After all, we do give a report" (int 3). The school leaders and the teachers gave accounts of their work situation to the superintendent, who checked whether plans were followed and results were achieved. Stig then tried to influence the schools through support and guidance. Looking back, Stig admitted that it would have been better with less control from his side: "I believe we should have given the schools the responsibility for the dialogue meetings from the beginning' (int 4).

\subsection{Authentic leadership: honesty and given trust}

Although the superintendent led the meetings, he did not pretend to have all the answers, and he wanted to hear the participants' experiences, views on practice, and suggestions for school development. There seemed to be psychological safety where spontaneous discussions emerged, as the participants openly expressed their opinions. The three school leaders confirmed this positive impression of the dialogues; for example, Clara said, "I felt we had a good dialogue all the way and that we asked to speak. Stig almost acted as a moderator" (int 3). The positive attitude also bears resonance among the other participants, exemplified by three team leaders: "I think it was very good ... it's important that someone comes and listen, so that is good" (dm 1 Aspen); "I find it very interesting, and the dialogue is good" ( $\mathrm{dm} 3 \mathrm{Birch}$ ); "I find it great, that you come around and that we have a conversation" (dm 1 Chestnut). Lastly, a teacher who was openly critical towards Stig said, "Regarding our leadership, they think that things are said clearly, and we do not think it's said clearly; so then, this type of meeting is the answer, I think: sit together and talk" (dm 1 Aspen). Here we find openness and honesty, which imply a trusting atmosphere where the participants are concerned with having a productive dialogue without being afraid of sanctions. Thus, the dialogue seemed to be, as Eikeland (2006, p. 227) recommends, open, critical, and constructive.

The superintendent and his advisor expressed similar views, both in interviews and in dialogue meetings. Stig said, "I believe that the impression is that it's been a risk-free forum to take up any issue, and also a forum where all participants have the genuine feeling to be seen by the superior" (int 4). Moreover, participants dared to talk about negative aspects of their schools. A team leader said they had students that were so afraid that "if that were my child, I would never in the world accept it" (dm 1 Chestnut) and another team leader criticised the school's lack of internal "dialogues" between the teachers ( $\mathrm{dm} 1 \mathrm{Birch}$ ). A teacher (mentioned in the previous paragraph) who found dialogue useful launched open criticism of the municipality and the superintendent:

For me, I perceive it emotionally very provocative, not to receive orders from central authorities, but it's what we do-we receive orders but never any praise. The things we believe we're doing well are never seen, the things that we really man- 
age to do [...] and this is partly a response to what our school leader says, that there are many negative attitudes towards the municipal management, or towards you who are managing us. (dm 1 Aspen)

\subsection{Empowerment by participation}

The superintendent did not put any constraints on who participated from the schools, and said,

In the management dialogue, we have invited, or at least thought, that the schools should decide who should participate. And we can see they have done it differently, so we have played the ball to them; the schools should have a say. (int 1)

The schools were sovereign to define participation, and they solved this differently, so the people Stig met during the meetings changed (from two to seven), not always to Stig's satisfaction. There were, however, clear expectations that the school leader met since the meeting was otherwise postponed. In addition to the school leader, team leaders, others in the leadership group, and others with central roles attended the meetings (see Appendix $\mathrm{C}$ for details on participation).

The superintendent mentioned two arguments for including several school representatives. First, to get a better view of what happened in the school, "we have gained more info than what just the school leader could have conveyed" (int 1). Broad representation and participation in dialogue meetings provide a better picture of the schools; more than a single school leader could have given. Second, to make it easier for the school leadership to take the dialogue further into the school, "the process goes smoother" (int 1). The participating school leaders also acknowledged this point. Still, some of the other schools included only two or three participants. When school leader Balder-who had many participants-heard this, he questioned why it was so: "When Stig perceives so much variation in the participation, I find it strange that he does not change the rules towards a standardised design. He could, for example, decide to meet all the team leaders or the team coordinators" (int 3).

The superintendent and the advisor agreed that broad participation alone did not yield a productive meeting since they deemed some meetings with few representatives valuable, and some meetings with many representatives rather inadequate. Thus, they were both unsure about the importance of the numbers of school representatives. Nevertheless, they thought it was vital that the schools could choose for themselves. Stig concluded that they should give the school leaders "a responsibility to achieve ideal participation" (int 3). Then, the dialogical intentions could be better achieved by giving more responsibility to the schools and thereby equalising the power balance. On the other hand, this could provide more power to the school leaders, whereas mandatory broad participation could provide more power to other school participants.

The superintendent commended the schools that were prepared and claimed it led to better meetings: "It seems like good preparations give an extra good momentum in the meetings" (note 2). Simultaneously, it empowers the schools in directing the meetings towards issues they would like to put on the agenda, and it can give voice to teachers that are not a part of the dialogue meetings. The school leaders said they wanted to be well prepared, but they readily admitted that their preparations varied. Stig noticed this variation and argued that some schools were not prepared at all, whereas "in other 
places, it's been so coordinated that the school leaders have almost submitted the minutes to the dialogue meeting in advance" (int 4). The advisor pinpointed the same a bit earlier: "It's very good that the school leadership team have collaborated, but it impedes the discussion when the school leader reads from a ready-made script, and when the team leaders only join in on the first vote" (note 3 ). According to these statements, preparation can restrict the autonomy of the participants, making them less free to talk and thereby giving a narrower image of the school.

On the other hand, many school leaders aim at building coherent leadership teams, and from a control model, it is natural to highlight team unity. Still, Clara endorsed openness: "What I like with the dialogue meetings is that there are more than me who can describe what we do and what the challenge is. I find it very good" (int 4). Openness and inclusion of different voices are more in line with a commitment model, empowering teachers. Several participants voiced their opinions. A team leader underlined that this was her meaning: "I think it's important to keep these- this is not discussed, this is my opinion-and continue to have the same areas for improvement" (dm 3 Birch). In another dialogue meeting, several participants explicitly stated that they allowed for disagreement, as a team leader said, "We certainly do not agree internally" (dm 3 Chestnut). Thus, dialogue meetings can be an arena for bringing internal differences out in the open, giving voice and empowerment to several participants.

\subsection{Trust and group climate in dialogue meetings}

As noted, there is, in general, a high level of mutual trust between superintendents and school leaders in Norway. Our findings support this view. The school leaders seem to have a close connection with their superintendent, as Clara stated, "We have much contact in leadership meetings, and the road is open between us" (int 3). In general, the group climate in the dialogue meetings was relaxed and cheerful, illustrated by jokes and laughter from the participants on several occasions. The participants said what they meant, discussing challenges with their different views, and allowing for disagreements. They talked openly about negative aspects in their schools, and many of the participants had their say. Additionally, the school leaders were satisfied with the dialogue meetings and thought they had a positive impact on their schools.

What might be considered of prominence in the dialogue meetings was the inclusion of the whole school leadership team, many of whom seldom had the chance to speak to Stig, let alone ask questions. The advisor said, "It seems that those who do not meet the municipal level so often-team leaders-think it's very good to participate in these discussions, and, with few exceptions, everyone has been very active" (note 2). The level of trust seems to increase when a group of people have an open dialogue. Reflecting on school issues with competence is essential for building trust towards each other and the system. School leader Balder also argued for broad participation by pointing towards openness and benevolence: "I wanted to bring along many, so in a way, as many as possible could get insight, and it was important for me to be transparent and they could feel that everything was for their good" (int 4).

Dialogue meetings seem to counter the low-trust-oriented form of cooperation between the municipal administration and school leaders. Even if issues concerning standardisation, results, and accountability appear in the meetings, they are not raised as a matter for inspection with possible sanctions but rather taken up for discussion and reflection about potential areas of improvement. When the participants discuss 
low scores on students' test results, the focus is on how to move forward, pedagogically. As noted by Stig: "It's a paradigm shift in pedagogical thinking that we can think about how to move forward. It's exciting" (dm 3 Chestnut). Low scores are not used as an impetus to implement a control regime, in which the school is to blame and must improve to avoid stricter controls and possible sanctions. Instead, low scores are a stimulus to take on a challenge and discuss how to move forward in collaboration with the superintendent. When quantitative measures are balanced with qualitative, in a surrounding of mutuality, responsibility and trust, an intelligent form of accountability can emerge.

\section{Discussion}

\subsection{Balancing trust and control}

Agenda setting is a significant part of exerting influence in the school governance chain. The superintendent is uniquely positioned, due to expertise, hierarchical position, and informational advantages, to influence agenda setting. A study of municipal school boards in the Nordic countries in 2011 revealed that superintendents were key agents in creating the agenda for school board meetings, and the Norwegian school board members perceived the superintendent and the administration to have a major influence on the school board's decisions (Moos and Paulsen 2014). This underscores the asymmetric relationships between the superintendent and other school actors. Generally, in asymmetric power relations, it is paramount that the strongest one-in this case, the superintendent-embodies trust-building motives by being open, supportive, and granting professional discretion to the subordinates (Tschannen-Moran 2014, p. 41).

The dialogue meetings, as framed in our study, show that the superintendent, despite control over the agenda, manages to create and maintain a trust-based climate during shifting participation in line with the commitment model. Trust is essential for constructive dialogue meetings: "Trust is necessary for effective cooperation and communication, the foundations for cohesive and productive relationships in organizations" (Tschannen-Moran and Hoy 2000, p. 549). When several of the key players participate in an open dialogue and build networks, psychological safety seems to be established. Moreover, as the participants talk together, reflect on school issues with competence, and form close relationships, it is likely that trust towards the system increase.

When the dialogue meetings are used to follow up and support schools in their endeavours to improve, like the findings in this study verifies, it is a trust-based form of meeting in line with the commitment model. The superintendent explicitly stated and showed that the intention was to support and follow up school development. $\mathrm{He}$ also wanted to give the schools control over the agenda. However, a certain degree of control is always present in dialogue meetings since the superintendent's job is to manage the schools. When school leaders report to the superintendent, the latter will document, evaluate, and follow up the results of the schools, following national policy documents. The dialogue meetings were not used for searching for irregularities and mistakes, a typical control activity (Paulsen and Høyer 2016). Elements of control appear, specifically related to the agenda of the dialogue meetings, but less so towards 
the schools, such as standardisation of teaching methods and results. Hence, it is fair to say that the dialogue meetings comprise no culture of control in where the bureaucratic nature of organisations takes over for professionalism (Tschannen-Moran 2014, p. 110).

\subsection{The crux of heterogeneous meetings}

The findings indicate that involving several people-at different levels of the hierarchy-in the dialogue meetings are of great value. We can say that the group of people from the municipality and the school forms something like a team, centred at each school. With psychological safety within these teams, the participants dare to speak their minds, revealing unsatisfactory practices, and reflecting over alternative perspectives. This enhances the learning climate in these teams. Moreover, with several participants, several people share experiences and evolve a shared understanding, and thus it is easier for school leaders to implement changes in their school. This finds support in empirical research, as "team-based dialogue meetings give a broader basis for shared understanding" (Roald 2010, p. 275). The superintendent acquires access to a broader view of what happens in the school and thereby has a chance to adapt strategies to the local setting, as insisted by Datnow (2002, p. 233). Team leaders and teachers are regarded as partners and resources to build upon when changing schools.

For people working in dispersed locations, heterogeneous meetings have proven effective to make sense of management dialogues (Henriksen 2018), and our findings presented above infer that trust enables empowerment and commitment in such a group setting. An open dialogue on issues that matter for the participants gives them a sense of value and belief that this is important. When the superintendent deals with the participants as professionals, takes their concerns seriously and reflects with them on the way forward, the participants are engaged and feel they have a say. Consequently, group participation is promoted to use the meetings as a venue for fostering empowerment and commitment.

\subsection{Implications for superintendent leadership}

We argue that superintendent leadership through regular dialogue meetings can foster trust-building, empowerment, and professional commitment. Participants from the schools find dialogues valuable when school issues and change are on the agenda. When several participants reflect together intending to develop schools, educational change is more easily achieved. Broad and heterogeneous participation empowers the participants. When the participants are honest, open, and not afraid of sanctions, they speak about weaknesses in their school. Thus, we argue that the dialogue meetings build trust within the system and are a means of achieving positive changes for schools.

The asymmetric power relations might make the participants from the schools afraid of criticising their superior, in fear of repercussions. The power is in the hands of the superintendent, who, in principle, can instruct the school leaders. In this setting, it emerges as paramount that the superintendent can establish psychological safety and 
build a trusting relationship with the core participants of the dialogues. It is a unique setting in which the superintendent can interact with the subordinates and thereby foster trust. Tschannen-Moran (2014) uses the concepts of cultivating trust and a culture of trust and underscores that the person in the superior position must embody trustbuilding motives in practice, by showing a sense of care, being open and flexible, and taking the subordinates' expectations seriously.

\section{Conclusion}

In her seminal work on local school reform strategy, Rosenholtz (1987) wrote:

Max Weber once posed a critical dilemma when he asked how one controls organizational participants to maximize effectiveness and efficiency and minimize the unhappiness this very need to control produces. This same dilemma exists today not only in large organizations but in schools as well. It serves as a meaningful backdrop for thinking about the potential conflicts that confront the current movement: those of standardization and autonomy, management by hierarchical control or facilitation of professionalism, mandatory versus voluntary change, and so forth. (p. 535)

Three decades later, we see the same dilemmas and conflicts in local school governance. The current study recommends implicitly directing more attention to a professional commitment model. Dialogue meetings between different levels within the municipality could help in this endeavour, and be the missing link in the governance chain, replacing a tradition in which only the school leader met with the municipal level.

\section{Appendix A}

See Table 1. 


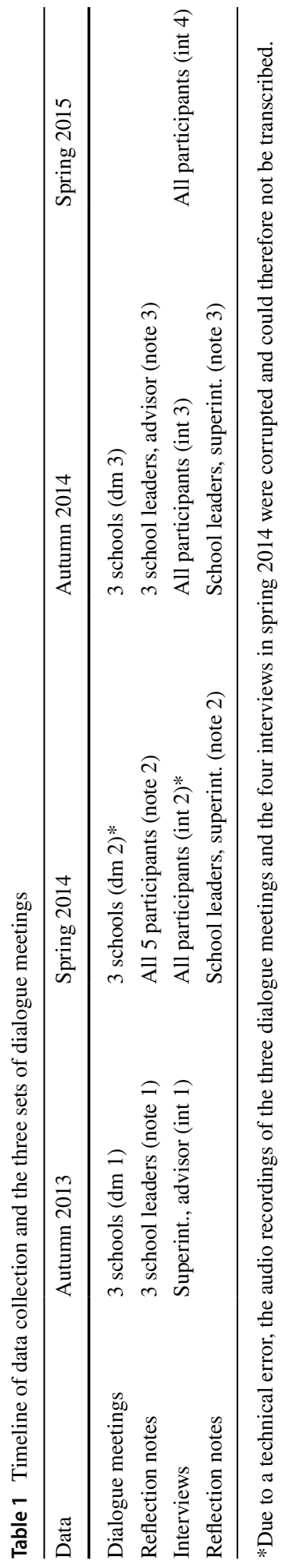




\section{Appendix B}

\section{See Table 2}

Table 2 Numbers of interviews and reflection notes from key participants

\begin{tabular}{llll}
\hline Participant & $\begin{array}{l}\text { Reflection notes } \\
\text { before interview }\end{array}$ & Interviews & $\begin{array}{l}\text { Reflection } \\
\text { notes after } \\
\text { interview }\end{array}$ \\
\hline Superintendent Stig & 1 & 2 & 2 \\
Advisor & 2 & 2 & 0 \\
$\begin{array}{l}\text { Superintendent and } \\
\text { advisor together }\end{array}$ & - & 3 & - \\
School leader Aud & 3 & 3 & 2 \\
School leader Balder & 3 & 3 & 2 \\
School leader Clara & 3 & 3 & 2 \\
Total & 12 & 16 & 8 \\
\hline
\end{tabular}

\section{Appendix C}

See Table 3.

Table 3 Participation in the dialogue meetings

\begin{tabular}{|c|c|c|c|}
\hline & Autumn 2013 & Spring 2014 & Autumn 2014 \\
\hline \multirow[t]{9}{*}{ Aspen School } & Superintendent & Superintendent & Superintendent \\
\hline & Advisor & Advisor & Advisor \\
\hline & PPT leader & CYU leader & CYU leader \\
\hline & PPT advisor & PPT advisor & School leader Aud \\
\hline & School leader Aud & School leader Aud & Team leader \\
\hline & 2 team leaders & 2 team leaders & Reading coach \\
\hline & Counsellor & Counsellor & Teacher \\
\hline & Reading coach & Safety representative & \\
\hline & Employee representative & Employee representative & \\
\hline \multirow[t]{9}{*}{ Birch School } & & Superintendent & Superintendent \\
\hline & Advisor & Advisor & Advisor \\
\hline & Action leader & CYU leader & CYU leader \\
\hline & PPT advisor & PPT advisor & School leader \\
\hline & School leader & School nurse & Balder \\
\hline & Balder & School leader & 3 team leaders \\
\hline & Assistant leader & Balder & Counsellor \\
\hline & 3 team leaders Counsellor & 3 team leaders & SFO leader \\
\hline & $\mathrm{AE}$ coordinator & AE coordinator & AE coordinator \\
\hline \multirow[t]{7}{*}{ Chestnut School } & Superintendent & Superintendent & Superintendent \\
\hline & Advisor & Advisor & Advisor \\
\hline & PPT leader & CYU leader & School leader Clara \\
\hline & Action leader & School leader Clara & 3 team leaders \\
\hline & School leader Clara & Assistant leader & SFO leader \\
\hline & 3 team leaders & 3 team leaders & AE coordinator \\
\hline & SFO leader & AE coordinator & \\
\hline
\end{tabular}

PPT Educational and psychological counselling service, $C Y U$ Child and Youth Unit, SFO Day care facilities for schoolchildren, $A E$ Adapted education 
Funding Open Access funding provided by OsloMet - Oslo Metropolitan University.

Open Access This article is licensed under a Creative Commons Attribution 4.0 International License, which permits use, sharing, adaptation, distribution and reproduction in any medium or format, as long as you give appropriate credit to the original author(s) and the source, provide a link to the Creative Commons licence, and indicate if changes were made. The images or other third party material in this article are included in the article's Creative Commons licence, unless indicated otherwise in a credit line to the material. If material is not included in the article's Creative Commons licence and your intended use is not permitted by statutory regulation or exceeds the permitted use, you will need to obtain permission directly from the copyright holder. To view a copy of this licence, visit http://creativecommons.org/licenses/by/4.0/.

\section{References}

Berg, P. J. (2015). Kommunal styring av skolen - En studie av styring som kommunikasjon i lys av Luhmanns systemteori. (PhD), NTNU, Trondheim.

Bogler, R., \& Somech, A. (2004). Influence of teacher empowerment on teachers' organizational commitment, professional commitment and organizational citizenship behavior in schools. Teaching and Teacher Education, 20(3), 277-289. https://doi.org/10.1016/j.tate.2004.02.003.

Bryk, A. S., \& Schneider, B. (2003). Trust in Schools: A Core Resource for School Reform. Educational Leadership, 60(6), 40-45.

Bukve, O. (2009). Styringsdialog - styring eller dialog? - Om vilkåra for samhandling ved fleirnivåstyring. Norsk statsvitenskapelig tidsskrift, 25(1), 59-71.

Carr, W., \& Kemmis, S. (1986). Becoming critical: education, knowledge, and action research. London: Falmer Press.

Cox, D. D., \& McLeod, S. (2014). Social media marketing and communications strategies for school superintendents. Journal of Educational Administration, 52(6), 850-868. https://doi.org/10.1108/ JEA-11-2012-0117.

Creswell, J. W., \& Creswell, J. D. (2018). Research design: qualitative, quantitative \& mixed methods approaches (5th ed.). Los Angeles, California: Sage.

Datnow, A. (2002). Can We Transplant Educational Reform, and Does It Last? Journal of Educational Change, 3(3-4), 215-239. https://doi.org/10.1023/A:1021221627854.

Datnow, A., Greene, J. C., \& Gannon-Slater, N. (2017). Data use for equity: implications for teaching, leadership, and policy. Journal of Educational Administration, 55(4), 354-360. https://doi.org/10.1108/ JEA-04-2017-0040.

Edmondson, A. C. (1999). Psychological safety and learning behavior in work teams. Administrative Science Quarterly, 44(2), 350-383. https://doi.org/10.2307/2666999.

Eikeland, O. (2006). The validity of action research - validity in action research. In K. Aagaard Nielsen \& L. Svensson (Eds.), Action and interactive research: beyond practice and theory (pp. 193-240). Maastricht: Shaker.

Engeland, Ø., \& Langfeldt, G. (2009). Forholdet mellom stat og kommune i styring av norsk utdanningspolitikk 1970-2008. Acta Didactica Norge, 3(1). doi: https://doi.org/10.5617/adno.1037

Grinshtain, Y., \& Gibton, D. (2018). Responsibility, authority, and accountability in school-based and non-school-based management: Principals' coping strategies. Journal of Educational Administration, 56(1), 2-17. https://doi.org/10.1108/JEA-01-2017-0005.

Helgøy, I., Homme, A., \& Gewirtz, S. (2007). Local Autonomy or State Control? Exploring the Effects of New Forms of Regulation in Education. European Educational Research Journal, 6(3), 198-202. https ://doi.org/10.2304/eerj.2007.6.3.198.

Henriksen, Ø. (2018). Making sense across levels in local school governance. Nordic Journal of Comparativeand International Education, 2(2-3), 119-133. https://doi.org/10.7577/njcie.2752.

Henriksen, Ø. H., \& Aas, M. (2020). Enhancing system thinking - a superintendent and three principals reflecting with a critical friend. Educational Action Research. Advance online publication. https://doi. org/10.1080/09650792.2020.1724813.

Herr, K., \& Anderson, G. L. (2005). Action Research Dissertation: A Guide for Students and Faculty. Thousand Oaks, CA.: SAGE. https://doi.org/10.4135/9781452226644.

Hjertø, K. B., \& Paulsen, J. M. (2017). Learning outcomes in leadership teams: The multi-level dynamics of mastery goal orientation, team psychological safety, and team potency. Human Performance, 30(1), 38-56. https://doi.org/10.1080/08959285.2016.1250765. 
Jøsendal, J. S., \& Langfjæran, D. (2009). Kom narmere! : sluttrapport fra FOU-prosjektet "Hvordan lykkes som skoleeier? om kommuner og fylkeskommuners arbeid for å фke elevenes laringsutbytte". https ://www.ks.no/globalassets/vedlegg-til-hvert-fagomrader/utdanning-og-oppvekst/skole/084013rapporthvordan-lykkes-som-skoleeier.pdf

Louis, K. S., \& Murphy, J. (2017). Trust, caring and organizational learning: the leader's role. Journal of Educational Administration, 55(1), 103-126. https://doi.org/10.1108/JEA-07-2016-0077.

Mayer, R. C., Davis, J. H., \& Schoorman, F. D. (1995). An integrative model of organizational trust. Academy of Management Review, 20(3), 709-734. https://doi.org/10.5465/amr.1995.9508080335.

Meyer, F., Le Fevre, D. M., \& Robinson, V. M. J. (2017). How leaders communicate their vulnerability: implications for trust building. International Journal of Educational Management, 31(2), 221-235. https://doi.org/10.1108/IJEM-11-2015-0150.

Miles, M. B., Huberman, A. M., \& Saldaña, J. (2014). Qualitative data analysis: a methods sourcebook (3rd ed.). Los Angeles: Sage.

Moos, L., \& Paulsen, J. M. (2014). School boards in the governance process. Cham: Springer. https://doi. org/10.1007/978-3-319-05494-0.

Moos, L., Johansson, O., Paulsen, J. M., Strand, M., \& Risku, M. (2016a). Democracy in complex networks: Political leaders and administrative professionals. In L. Moos, E. Nihlfors, \& J. M. Paulsen (Eds.), Nordic superintendents: Agents in a broken chain (pp. 177-205). Cham: Springer. https://doi. org/10.1007/978-3-319-25106-6_6.

Moos, L., Nihlfors, E., \& Paulsen, J. M., (Eds.). (2016b). Nordic superintendents: Agents in a broken chain. Cham: Springer. https://doi.org/10.1007/978-3-319-25106-6.

Paulsen, J. M., \& Hjertø, K. B. (2019). Strengthening school principals' professional development through effective school ownership in Norwegian municipalities. International Journal of Educational Management, 33(5), 939-953. https://doi.org/10.1108/IJEM-08-2017-0221.

Paulsen, J. M., \& Høyer, H. C. (2016). External control and professional trust in norwegian school governing: Synthesis from a nordic research project. Nordic Studies in Education, 36(2), 86-102. https://doi. org/10.18261/issn.1891-5949-2016-02-02.

Paulsen, J. M., Johansson, O., Moos, L., Nihlfors, E., \& Risku, M. (2014). Superintendent leadership under shifting governance regimes. International Journal of Educational Management, 28(7), 812-822. https ://doi.org/10.1108/IJEM-07-2013-0103.

Roald, K. (2010). Kvalitetsvurdering som organisasjonslaring mellom skole og skoleeigar. (Ph.d.), University of Bergen, Bergen.

Rosenholtz, S. J. (1987). Education reform strategies: Will they increase teacher commitment? American Journal of Education, 95(4), 534-562. https://doi.org/10.1086/444325.

Rowan, B. (1990). Commitment and control: Alternative strategies for the organizational design of schools. Review of Research in Education, 16, 353-389. https://doi.org/10.2307/1167356.

Rowan, B., \& Miller, R. J. (2007). Organizational Strategies for Promoting Instructional Change: Implementation Dynamics in Schools Working with Comprehensive School Reform Providers. American Educational Research Journal, 44(2), 252-297. https://doi.org/10.3102/0002831207302498.

Sahlberg, P. (2011). The Fourth Way of Finland. Journal of Educational Change, 12(2), 173-185. https:// doi.org/10.1007/s10833-011-9157-y.

Sørhaug, T. (1996). Om ledelse. Makt og tillit i moderne organisering. Oslo: Universitetsforlaget.

Tschannen-Moran, M. (2014). Trust matters: Leadership for successful schools (2nd ed.). San Francisco:Jossey-Bass.

Tschannen-Moran, M., \& Hoy, W. K. (2000). A Multidisciplinary Analysis of the Nature, Meaning, and Measurement of Trust. Review of Educational Research, 70(4), 547-593. https://doi. org/10.2307/1170781.

Weiner, J. M., \& Woulfin, S. L. (2017). Controlled autonomy: novice principals' schema for district control and school autonomy. Journal of Educational Administration, 55(3), 334-350. https://doi.org/10.1108/ JEA-03-2016-0032.

Xia, J., Shen, J., \& Sun, J. (2020). Tight, Loose, or Decoupling? A National Study of the Decision-Making Power Relationship Between District Central Offices and School Principals. Educational Administration Quarterly, 56(3), 396-434. https://doi.org/10.1177/0013161X19851174.

Publisher's Note Springer Nature remains neutral with regard to jurisdictional claims in published maps and institutional affiliations. 